\title{
ESTIMATING MANGROVE FOREST DENSITY USING GAP FRACTION METHOD AND VEGETATION TRANSFORMATION INDICES APPROACH
}

\author{
N. Khakhim a, A. C. P. Putra ${ }^{b}$, T. U. Widhaningtyas ${ }^{\text {b }}$ \\ ${ }^{a}$ Faculty of Geography, Universitas Gadjah Mada, Yogyakarta, Indonesia \\ ${ }^{b}$ Remote Sensing Department, Earthline, Jakarta, Indonesia
}

\section{Article Info:}

Received: 14 Dec 2016

in revised form: 31 May 2017

Accepted: 3 November 2017

Available Online: 30 April 2018

\section{Keywords:}

Mapping, Estimate, Remote

Sensing, Mangrove Forest, Gap

Fraction, Landsat-8 OLI

Corresponding Author:

Nurul Khakhim

Faculty of Geography, Universitas

Gadjah Mada, Yogyakarta

Email: nurulk@ugm.ac.id

\begin{abstract}
Mangrove forest represented a coastal ecosystem in Indonesia. Theoretical validation and in-field measurement by calculating the number of trees and the density data that was validated through remote sensing would not be appropriate because the remote sensing recorded canopy density and not tree stands. New method canopy photography or gap fraction method was the technique to predict sun radiation using the photograph taken upward through extremely wide lens and classification object image. The objectives of the study were (1) to examine the acuracy of the estimation of the mangrove forest density using vegetation index transformation, and (2) to map the mangrove forest condition. The location of the study was Alas Purwo Resort Grajagan National Park area. The material of the study was Landsat-8 OLI image recorded on January 19th, 2016 using SAVI vegetation index transformation method. Gap fraction filed measurement method was a new method in Indonesia. The results of the study showed that the regression of the SAVI index between index transformation value and in-field condition $\left(R^{2}\right)$ was 0.566 , the forest density estimation resulting from the SAVI index transformation had the RMSE of 2.334178 and the density of the mangrove forest in Grajagan Bay of the Alas Purwo National Park included low density of 0-12.5\% (30.42 ha), medium density of 12.6-25\% (116.55 ha), and high density of 25.1-37.6\% (463.68 ha).
\end{abstract}

Copyright (C) 2018 GJGP-UNDIP This open access article is distributed under Creative Commons Attribution (CC-BY-NC-SA) 4.0 International license.

Khakhim, N., Putra, A, C, P., \& Widhaningtyas, T, U. (2018). Estimating mangrove forest density using gap fraction method and vegetation transformation indices approach. Geoplanning: Journal of Geomatics and Planning, 5(1), 35-42. doi: 10.14710/geoplanning.5.1.35-42

\section{INTRODUCTION}

Indonesia had a very wide coastal area with $95.181 \mathrm{~km}$ coastal line. Mangrove forest represented costal ecosystem and formed because of the presence of wave protection, fresh water input, sedimentation, tidal water flow, and warm temperature (Walsh, 1974). The mangrove forest in Grajagan Bay represented the most natural mangrove forest in Java Island (Sudarmadji, 2011). A part of the mangrove forest belonged to Alas Purwo National Park or to Grajagan Resort. According to the decree of the Minister of Forestry No. 283 KPTS-II/1992 Alas Purwo National Park was a conservation area.

Remote sensing was considered to be more effective in mapping mangrove condition than a conventional or terrestrial method. According to (Fawzi, 2015) the remote sensing of the mangrove forest was able to provide detailed physical aspects of the forest such as species, zoning, change in land use arrangement, and mangrove physical mapping. According to (Lee \& Yeh, 2009) mangrove had unique spectral reflection representing the combination of ground, water and vegetation because the mangrove grew in coastal area. Additionally, the basic reflection of mangrove canopy also influenced the spectral reflection of the mangrove (Kuenzer, Bluemel, Gebhardt, Quoc, \& Dech, 2011). Forest density could be estimated in the remote sensing using vegetation index transformation approach. The vegetation index transformation was a mathematical model developed to estimate forest density (Danoedoro, 2012). The objectives of the study were to examine the accuracy of the estimation of mangrove forest density using remote sensing with 
vegetation index transformation approach and to map the mangrove forest density in Grajagan Bay of Alas Purwo National Park.

Theoretical validation and in-field measurement by calculating the number of trees and the density data that was validated through remote sensing would not be appropriate because the remote sensing recorded canopy density and not tree stands. Therefore, a new method of gap fraction or hemispherical photography that was well-known as fisheye photography or canopy photography was the technique to predict sun radiation using the photograph taken upward through extremely wide lens (Rich, 1990). The resulting perspective was usually close to 180 degree that covered all sky directions. The resulting photographs recorded sky obstruction geometry by vegetation canopy or other close features. The geometry could measure objects exactly and used to calculate the sun radiation transmitted through the vegetation canopy and also to predict the canopy structure aspects such as LAI (leaf area index). The measurement of the canopy width using the gap fraction was based on the calculation of observable sky proportion as the function of sky direction with the canopy fraction recorded by the photographs. Scientists began to develop threshold method to separate canopy types through hemispherical photographs. The factor that influenced the classification of objects was the exposure of the taken photographs (Jonckheere, Nackaerts, Muys, \& Coppin, 2005). The classification of the photographs involved picture pixels representing both observable and non-observable sky directions with the intensity value of the pixels above the classified threshold as the intensity value of the pixels and observed below the threshold classified as non-observable. Recently, advancement has been made in developing automatic threshold algorithm. However, there were still many things to do till the technique was fully applicable (Inoue, Yamamoto, Mizoue, \& Kawahara, 2002).

The gap fraction of the hemispherical photography was useful in making the measurement of the canopy parameter easier through remote sensing, such as LAI (leaf area index) to find out the productivity of a plant calculated on the basis of the width of its leaves for photosynthesis per land surface unit (watson, 1947) (Jonckheere et al., 2004). The canopy width played an important role in identifying the information through the remote sensing. In the gap fraction method some assumed that leaf element was uneven so that there was significant difference between width leaf and needle-shape leaf (Smith, 1991) (Bolstad \& Gower, 1990).

\section{DATA AND METHODS}

\subsection{Study Area}

The location of the study was Grajagan Bay of Alas Purwo National Park. It was geographically situated at $114^{\circ} 13^{\prime} 20,203^{\prime \prime}$ east longitude, $114^{\circ} 20^{\prime} 45,979^{\prime \prime}$ east longitude and $8^{\circ} 35^{\prime} 52,79^{\prime \prime}$ south latitude and $8^{\circ} 37^{\prime} 28,697$ south latitude as indicated in the map (Figure 1). Dominant water movement taking place in estuary was sea water that salinity would influence the zoning of the location. Therefore, the results of infield observation of the zoning of the mangrove forest in Grajagan Bay could be classified into 2, south zone and north zone on the basis of the boundary of the sea water of the estuary. Based on the in-field observation there were 15 species of the mangrove of the Grajagan Bay of Alas Purwo National Park, but according to Wetland International there were 27 species spreading in the National Park and Perum Perhutani.

\subsection{Image Processing}

The study used the data of Landsat-8 OLI with 2 sensors carried by Landsat of 8th generation, which were OLI and Thermal. However, it used the OLI sensor. The Landsat- 9 OLI consisted of 9 bands and according to (Irons, 2015) with the following details: coastal band $(0.43-0.45 \mu \mathrm{m})$, blue band $(0.450-0.51 \mu \mathrm{m})$, green band (0.53-0.59 $\mu \mathrm{m})$, red band (0.64-0.67 $\mu \mathrm{m})$, near infrared band (0.85-0.88 $\mu \mathrm{m})$, SWIR1 band (1.57-1.65 $\mu \mathrm{m})$, SWIR2 band (2.11-2.29 $\mu \mathrm{m})$ ), panchromatic band (0.50-0.68 $\mu \mathrm{m}))$, and cirrus band (1.36-1.38 $\mu \mathrm{m})$ with the resolution of 30 meters for multispectral imaging and 15 meters for panchromatic imaging. The reason for the use of the Landsat-8 OLI image was that it had complete band with minimum cloud coverage of $11.6 \%$ on ground and when the cloud coverage on the ground was $>30 \%$, the cloud would cover targeted object and the imaging result was useless. And then, radiometric and atmospheric corrections were made 
to obtain biophysical parameters (Jensen \& Lulla, 1987). The atmospheric correction was made using histogram adjustment method. The histogram adjustment method was easy and simple to use by discarding the offset value of the image (Danoedoro, 2012). The image was processed using software ENVI 4.8.

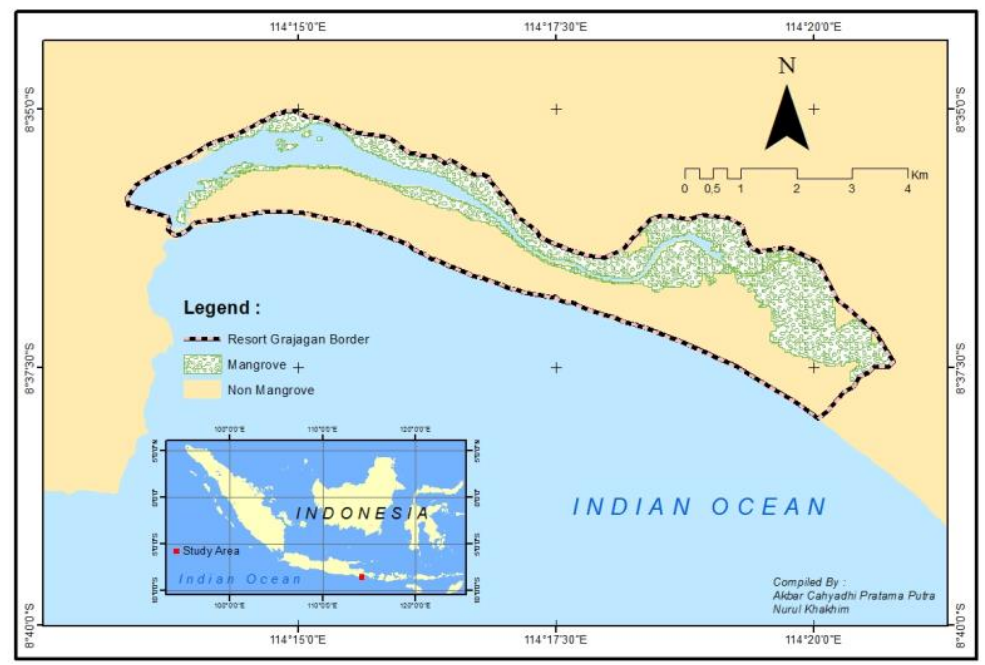

Figure 1. The location of the study in Grajagan Bay of Alas Purwo National Park.

\subsection{Field Measurement}

The activity of the field measurement was conducted in April 2016 in Alas Purwo National Park area. The measurement was made using DSLR camera Nikon D5100 with 18-55 mm lens and additional fisheye converter lens to change the resulting image into fisheye image (Figure 2a). The portraying was conducted using the fisheye lens because it was the easiest and more appropriate lens for processing the resulting canopy density image with the software can eye.

The data of the canopy density was processed using the software can eye because it was a new software and gave more appropriate results with the in-field condition. It was necessary in the in-field portraying to consider the mean height that was breast height on squat position (Figure $2 b$ ).

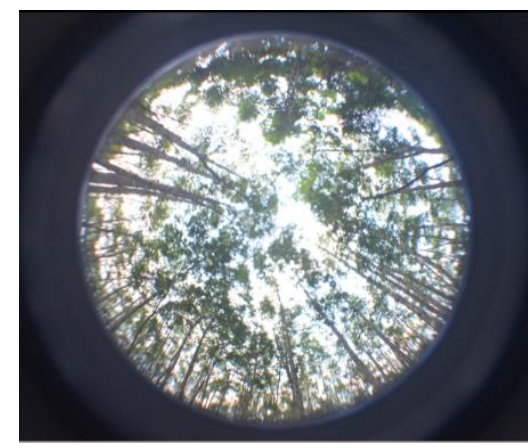

(a)

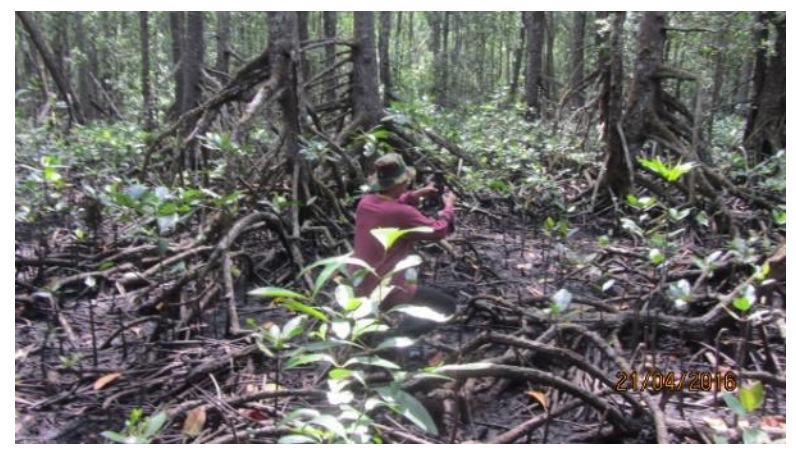

(b)

Figure 2. (a) Field measurement. (b) The results of vertical fisheye portraying and Figure (b). The in-field portraying process.

\subsection{Field Measurement}

Vegetation transformation index used in the study was index SAVI (soil adjusted vegetation index). The SAVI vegetation index was the best one considering the factor of land influence (L). According to (Jensen \& Lulla, 1987), (Danoedoro, 2012) the SAVI vegetation index was able to reduce land background because of the presence of the factor of land spectral noise during atmosphere correction. The formula of the SAVI (Eq.1) vegetation index is: 


$$
S A V I=\frac{(1+L)(N I R-R e d)}{N I R+R e d+L}
$$

The factor of land influence ( $L$ ) used in the study was 0.5 because it was the result of the field identification of the mangrove forest, which was moderately dense. Additionally, it was the most common practice to use the value because it could accommodate both low and high vegetation areas (Champagne in Ilham, 2012). The process was carried out using the SAVI vegetation index in which NIR was near infrared band and RED was red band in the Landsat- 8 image resulting from the atmosphere correction processing. The results of the processing of the SAVI vegetation index transformation were statistically analyzed using regression and correlation methods to find out the correlation between the results of the estimation of the image and the in-field condition. The regression analysis resulted in the equation $Y=a x+b$ to develop forest density estimation model.

\section{RESULTS AND DISCUSSION}

In remote sensing the recorded forest density was the canopy density so that it was more appropriate and the results were more accurate. If the measurement was conducted using canopy approach, the remote sensing recorded the canopy density and not the density of tree stands so that a new method of gap fraction or hemispherical photography was developed. The gap fraction method was new method and has not been widely used in Indonesia. The measurement using this method was very simple because it used a camera and fisheye lens and the photographs were taken upward or downward depending on the objective of the photography. The results of the upward photographs might be seen in (Figure 2a). The study used the upward photography to avoid noises of other objects in the resulting photographs. The average in-field canopy density was $21.6 \%$ or 0.216 of 46 distributed sample points. The resulting canopy density was processed using can eye software accessible in http://www6.paca.inra.fr/can-eye (Weiss, 2002). The process was carried out by tracing the resulting photographs taken using fisheye lens that tended to be convex into low watermark canopy density as reference so that the results of the classification of the canopy and non-canopy density would be very different as illustrated in (Figures $3 a$ and $3 b$ ).

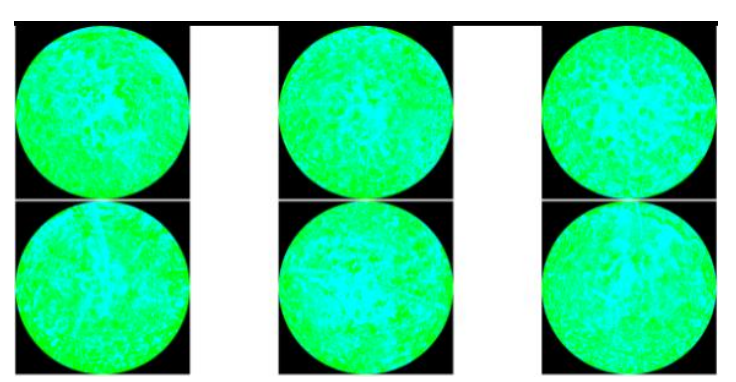

(a)

\begin{tabular}{||l|c||}
\hline File & $\begin{array}{c}\text { FCover } \\
(\%)\end{array}$ \\
\hline DSC_0357.JPG & 20.3 \\
\hline DSC_0358.JPG & 21.8 \\
\hline DSC_0359.JPG & 15.9 \\
\hline DSC_0360.JPG & 19.5 \\
\hline DSC_0361.JPG & 9.1 \\
\hline DSC_0362.JPG & 16.0 \\
\hline
\end{tabular}

(b)

Figure 3. (a) The scheme of the processing of the forest density. (b) The results of the classification of the canopy and non-canopy density and Figure (b). The results of the processing of forest density.

According to (Jonckheere et al., 2005), the classifying process was based on the threshold given by the processing software. The classification would give canopy density through the gap between sky and canopy object. The classification would influence the width of the coverage area of the lens, which was increasingly wider and close to $180^{\circ}$ and the results would be better because the influencing factors of the density were the angle of sun and the ability of the camera in catching objects such as over exposure or under exposure. The photographs were usually made using auto method that the classification of the objects was based on the incoming light into the camera considered to be the same and there was not any under exposure or overexposure. The more the under exposure influenced the density, the higher the density would be, while the more the over exposure influenced the density, the smaller the classified objects would be. 
The resulting density of the in-field measurement would be used as observation data that would subsequently be used in statistical test using regression to find out the correlation between the in-field density and the estimated data resulting from the image processing using vegetation index transformation, which was SAVI because the SAVI was according to (Putra \& Khakhim, 2016) was appropriate method in mangrove forest density mapping with good accuracy and appropriate with the in-field condition. The accuracy of the SAVI reached $80 \%$. It was consistent with other study by (Murti \& others, 2013) in which a representation was made among RVI, NDVI and SAVI and the results were indicative of the canopy density with the accuracy above $80 \%$.

The results of the regression (R2) of the observation results of the image processing showed that the regression (R2) was 0.566 and the equation $Y=107.96 x+5.2859$ as illustrated in (Figure 4). Consequently, the equation $Y=107.96 x+5.2859$ was applicable in spatially mapping the canopy density. The regression value above would result in canopy density estimation model in mangrove forest that was based on the estimation results of the regression equation between the in-field measurement sample and the condition of the remote sensing. Actually, a linear regression might be carried out only by observing how appropriate the estimation results of the long distance image and the in-field actual condition. Therefore, the regression $\mathrm{Y}=\mathrm{ax}+\mathrm{b}$ would give the regression value (R2) that enables us to find out the correlation. The closer was the correlation $(R)$, the more appropriate it would be with the in-field condition. Thus, the resulting correlation of the regression model was close and able to estimate the mangrove forest density using the vegetation index transformation SAVI. There were 30 samples used in the regression to develop the forest density estimation model.

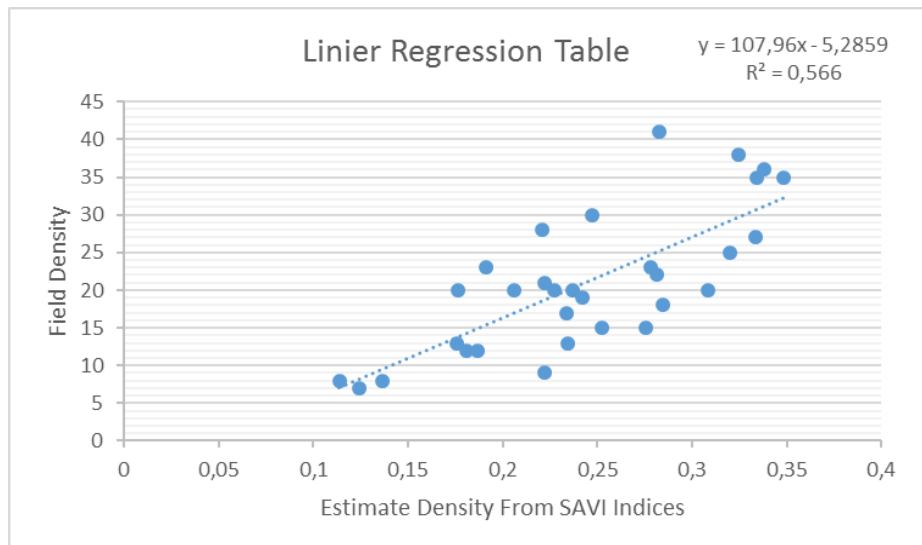

Figure 4. The regression of the results of the in-field density measurement and the results of the vegetation index transformation processing.

The results of the regression equation would be returned to the long distance image in which the $x$ value would be substituted by the result of the vegetation index transformation processing SAVI and it would give the estimated forest density. The estimated forest density might be observed in (Figure 5). The resulting mangrove forest density was classified in 3: low, medium and high. Based on the density there were low density forest (0-12.5\%), medium density forest (12.6-25\%), and high density forest (25.1-37.6\%) in (Table 1).

Table 1. The Result Table of Density Mangrove

\begin{tabular}{lrrr} 
Density Class & Range Class (\%) & Extensive (ha) & Pixels \\
Low & $0-12,5$ & 30,42 & 338 \\
\hline Medium & $12,6-25$ & 116,55 & 1295 \\
\hline High & $25,1-37,6$ & 463,68 & 5152 \\
\hline Total & & 610,65 & 6785 \\
\hline
\end{tabular}


It was necessary to find out the accuracy of the resulting forest density in order to find the error of the forest density estimation. The accuracy was measured using RMSE (roots mean square error) method commonly used in the remote sensing. According to (Kamal, Hartono, Wicaksono, Adi, \& Arjasakusuma, 2016), the method was used to predict the visual error between the data resulting from the observation and the estimation data. The bigger was the RMSE, the lower the resulting accuracy would be. The number of the samples used in the accuracy test was 14 samples. There supposed to be 15 samples ideally to find out the accuracy of the samples. However, 14 samples were used because there in-field sampling failed to comlete the number. However, 14 samples were still considered to give accuracy in the measurement. The location of the sample drawing for the accuracy test must be widely separated to the location of the samples for the estimation model for more ideal accuracy and did not have any significant impact on the model, if the estimated model sample and the accuracy were close, the resulting accuracy would be better and hence it was less representative.

The results of the calculation of the accuracy showed that the RMSE was 2.334178. According to (Makridakis et al., 1982) the low RMSE value indicated that the resulting value variation of the estimation model was close to its observation variation. The higher was the regression value of the in-field observation results and the estimated results were high, the better the resulting RMSI would be. Good RMSE was the one with low value. The lower was the RMSI value, the better it was. Based on (Putra \& Khakhim, 2016), among the RMSE SAVI value and other vegetation index transformation methods the best was the SAVI with the lowest RMSE value. Therefore, the RMSE value of 2.334178 was low enough for a model to be accurate. The lower was the RMSE value, the better it would be. In other words, the closer was it to 0.00 , the better it would be (Kamal et al., 2016). The 1:1 line in (Figure 5) was helpful in understanding the estimation results of the forest density whether it was underestimate or overestimate. It was a red and diagonally dividing line indicative of overestimation or underestimation. If it was underestimated, the sample distribution would be concentrated in the in-field observation and vice versa. The results of the study showed that the forest density was underestimated and the in-field density was $>25 \%$ in which there were some samples concentrated in and heading to the underestimated density. It was influenced by the tidal condition of the forest.

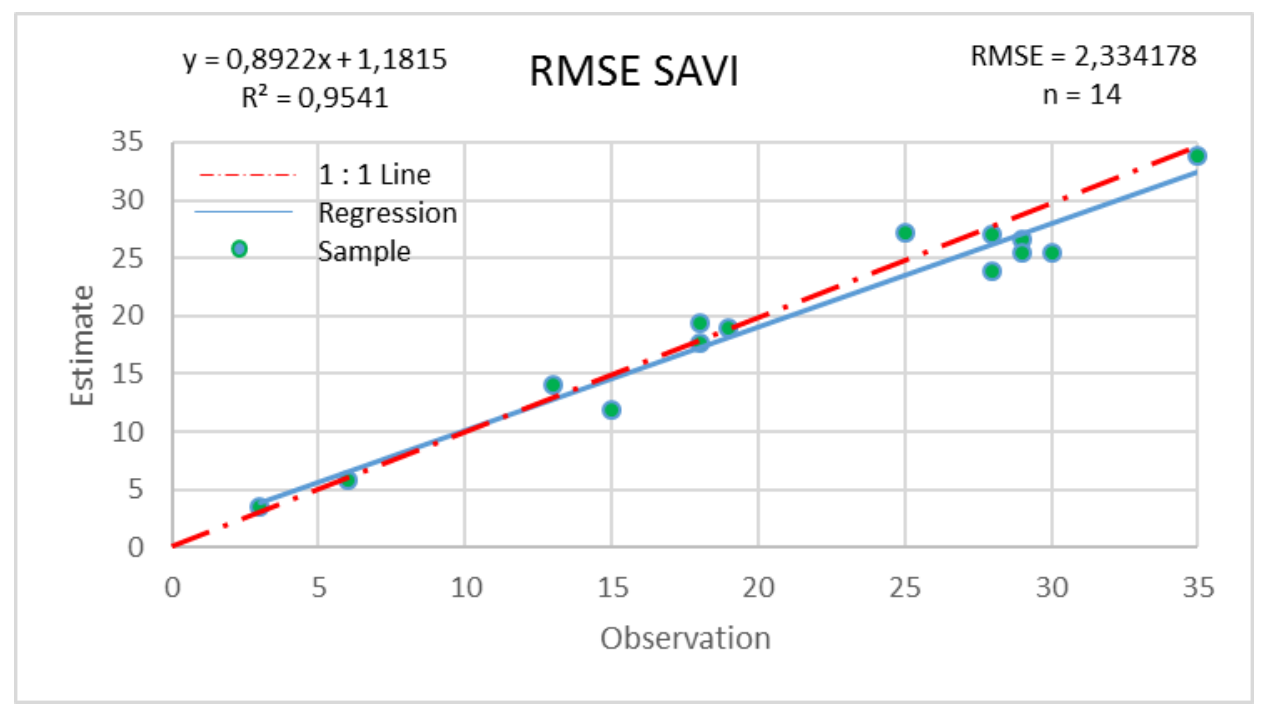

Figure 5. The results of the calculation of the RMSE (root means square error) of the vegetation index transformation SAVI of mangrove forest. 


\section{CONCLUSION}

If the forest density was measured using remote sensing, the object for the measurement was the canopy that was measured through spectral reflection so that it was the forest canopy density that was measured in the measurement. The forest canopy density was measured using gap fraction method or hemispherical photography method. The method was more appropriate in identifying the forest density, especially the canopy density because it used the covering width of hemispherical lens. The samples of the study were measured using the vegetation index transformation SAVI that could give in-field mean canopy density of $21.6 \%$, while the estimated density was $25 \%$ and the resulting RMSE was 2.334178 and categorized into good enough.

\section{ACKNOWLEDGMENTS}

We would like to thank Mr. Muhammad Kamal S.Si., M.GIS., Ph.D who knew the new gap fraction method, the Office of Alas Purwo National Park for the opportunity to conduct a research, and Mr. Supangat, Mr. Tri, Mr. Marzuki, Mr. Haryanto, and Toro who have helped us in drawing samples in field.

\section{REFERENCES}

Bolstad, P. V, \& Gower, S. T. (1990). Estimation of leaf area index in fourteen southern Wisconsin forest stands using a portable radiometer. Tree Physiology, 7(1-2-3-4), 115-124. article. https://doi.org/10.1093/treephys/7.1-2-3-4.115 [Crossref]

Danoedoro, P. (2012). Pengantar penginderaan jauh digital. Penerbit Andi, Yogyakarta.

Fawzi, N. I. (2015). Penginderaan Jauh Untuk Ekologi dan Konservasi. Yogyakarta: University Gadjah Mada.

Ilham, M. (2012). Pendekatan Multiregresi Indeks Vegetasi Untuk Pendugaan Stok Karbon. Institute Technology Bandung.

Inoue, A., Yamamoto, K., Mizoue, N., \& Kawahara, Y. (2002). Estimation of Relative lilluminance using Digital Hemispherical Photography. Journal of Forest Planning, 8(2), 67-70.

Irons, J. R. (2015). Operational Land Imager (OLI). Retrieved from https://landsat.gsfc.nasa.gov/operationalland-imager-oli/

Jensen, J. R., \& Lulla, K. (1987). Introductory digital image processing: a remote sensing perspective. article.

Jonckheere, I., Fleck, S., Nackaerts, K., Muys, B., Coppin, P., Weiss, M., \& Baret, F. (2004). Review of methods for in situ leaf area index determination. Agricultural and Forest Meteorology, 121(1-2), 1935. [Crossref]

Jonckheere, I., Nackaerts, K., Muys, B., \& Coppin, P. (2005). Assessment of automatic gap fraction estimation of forests from digital hemispherical photography. Agricultural and Forest Meteorology, 132(1-2), 96-114. [Crossref]

Kamal, M., Hartono, H., Wicaksono, P., Adi, N. S., \& Arjasakusuma, S. (2016). Assessment of Mangrove Forest Degradation through Canopy Fractional Cover in Karimunjawa Island, Central Java, Indonesia. Geoplanning: Journal of Geomatics and Planning, 3(2), 107. [Crossref]

Keputusan Menteri Kehutanan. 1992. No. 283/KPTS-II/1992 tanggal 26 februari 1992 Penentuan Taman Nasional Alas Purwo Sebagai Kawasan Suaka Alam dan Konservasi, Kabupaten Banyuwangi, Jawa Timur. Jakarta : Departemen Kehutanan

Kuenzer, C., Bluemel, A., Gebhardt, S., Quoc, T. V., \& Dech, S. (2011). Remote Sensing of Mangrove Ecosystems: A Review. Remote Sensing, 3(5), 878-928. [Crossref]

Lee, T.-M., \& Yeh, H.-C. (2009). Applying remote sensing techniques to monitor shifting wetland vegetation: A case study of Danshui River estuary mangrove communities, Taiwan. Ecological Engineering, 35(4), 487-496. [Crossref]

Makridakis, S., Andersen, A., Carbone, R., Fildes, R., Hibon, M., Lewandowski, R., ... Winkler, R. (1982). The accuracy of extrapolation (time series) methods: Results of a forecasting competition. Journal of Forecasting, 1(2), 111-153. [Crossref]

Murti, S. H., \& others. (2013). Pemanfaatan Citra ALOS AVNIR-2 untuk Klasifikasi Kerapatan Kanopi Hutan Mangrove berdasarkan Transformasi Indeks Vegetasi Di Delta Wulan Demak, Jawa Tengah (phdthesis). Universitas Gadjah Mada. 
Putra, A. C. P., \& Khakhim, N. (2016). Pemetaan kerapatan kanopi hutan mangrove menggunakan citra landsat-8 oli di wilayah pengelolaan (resort grajagan), taman nasional alas purwo, kabupaten banyuwangi, jawa timur (phdthesis). Universitas Gadjah Mada.

Rich, P. M. (1990). Characterizing plant canopies with hemispherical photographs. Remote Sensing Reviews, 5(1), 13-29. [Crossref]

Smith, N. J. (1991). Predicting radiation attenuation in stands of Douglas-fir. Forest Science, 37(5), 12131223.

Sudarmadji, I. (2011). Identifikasi lahan dan potensi hutan mangrove di bagian timur Propinsi Jawa Timur. Bonoworo Wetlands, 1(1), 7-13.

Walsh, G. E. (1974). Mangroves: a review. In Ecology of halophytes (pp. 51-174). incollection, Elsevier.

Watson, D. J. (1947). Comparative Physiological Studies on the Growth of Field Crops: I. Variation in Net Assimilation Rate and Leaf Area between Species and Varieties, and within and between Years. Annals of Botany, 11(1), 41-76. [Crossref]

Weiss, M. (2002). EYE-CAN User Guide (techreport) 